\section{Surgically induced astigmatism in phacoemulsification, pars plana vitrectomy, and combined phacoemulsification and vitrectomy: a comparative study}

${ }^{1}$ Department of

Ophthalmology and Visual Sciences, The Chinese University of Hong Kong, Hong Kong, The People's Republic of China

${ }^{2}$ Hospital Authority Ophthalmic Services, Hong Kong Eye Hospital, Hong Kong, The People's Republic of China

Correspondence: CYF Yuen, Department of

Ophthalmology and Visual Sciences,

The Chinese University of Hong Kong,

3/F,

Hong Kong Eye Hospital,

147K, Argyle Street, Kowloon, Hong Kong.

Tel: + 8522762 3157;

Fax: + 85227159490 .

E-mail: can_yuen@

yahoo.com.hk

Received: 31 October 2007 Accepted in revised form: 4 February 2008

Published online: 7 March 2008

Financial and proprietary interest: None.
Abstract

Purpose To study the surgically induced astigmatism (SIA) in combined phacoemulsification and vitrectomy, and compare with that when either procedure is performed alone.

Methods This is a prospective comparative interventional trial comprising of 60 eyes of 60 consecutive patients with cataract and/or vitreo-retinal pathology. They were divided equally into three groups based on the type of procedure: Group A, phacoemulsification alone group, using a $3.0-3.2 \mathrm{~mm}$ wide unsutured sclero-corneal tunnel incision at $\mathbf{1 . 0} \mathrm{mm}$ post-limbus at $\mathbf{1 0}$ o'clock; Group B, par plana vitrectomy alone group, using three sclerotomies at $3.5 \mathrm{~mm}$ post-limbus at 2 , 8 , and 10 o'clock (right eye) or at 2, 4, and 10 o'clock (left eye) positions; and Group C, combined phacoemulsification and pars plana vitrectomy group. Main outcome measures were the amplitude (K-induced) and the axis of SIA calculated by rectangular coordinate method using the Holladay-Cravy-Koch formula.

Results The mean K-induced amplitudes were $0.19 \pm 0.14 \mathrm{D}, 0.17 \pm 0.11 \mathrm{D}$, and $0.23 \pm 0.19 \mathrm{D}$ for groups $\mathrm{A}, \mathrm{B}$, and $\mathrm{C}$, respectively. The range of $\mathrm{K}$-induced amplitudes for the entire cohort was 0.00-0.77 D. No overall statistically significant differences in the pre- and postoperative topographic astigmatism amplitudes and the K-induced between groups A, B, and C were found (all $P>0.05$ ). Minor shifts, of
CYF Yuen 1,2, BTO Cheung 1,2, C-W Tsang 1,2, RF Lam ${ }^{1,2}$, NB Baig ${ }^{1,2}$ and DSC Lam ${ }^{1,2}$ doubtful clinical significance, in the axes of SIA were present.

Conclusions Combined phacoemulsification and pars plana vitrectomy does not induce significant astigmatic change per se, and its amount is similar to that when either procedure is performed alone.

Eye (2009) 23, 576-580; doi:10.1038/eye.2008.57; published online 7 March 2008

Keywords: surgically induced astigmatism; phacoemulsification; vitrectomy; corneal topography

\section{Introduction}

While combined phacoemulsification and pars plana vitrectomy has been advocated as an effective and safe procedure to handle cases with both cataract and posterior segment disorders, ${ }^{1-3}$ refractive cataract surgery which incorporates astigmatic keratotomy with phacoemulsification is gaining popularity in recent times. This prompted us to question whether such an approach can also be used in eyes with concurrent cataract, posterior segment disorders, and significant astigmatism. To answer this, we must first know the surgically induced astigmatism (SIA) after combined surgery with phacoemulsification and pars plana vitrectomy. Although previous studies have shown that the SIA for phacoemulsification by scleral tunnel ${ }^{4-6}$ and for pars plana vitrectomy $\mathrm{y}^{7-10}$ is minimal, one can 
never assume that the same conclusion holds when the two procedures are combined.

The aim of the present study is to study the SIA after combined phacoemulsification and vitrectomy, and compare with that when either procedure is performed alone.

\section{Materials and methods}

This is a prospective, comparative, interventional study conducted at the Hong Kong Eye Hospital, a tertiary specialist hospital in the region. The study protocol was approved by the Department of Ophthalmology and Visual Sciences of the Chinese University of Hong Kong. The study followed the tenets of Declaration of Helsinki and written consent was obtained from all participating patients. We certify that all applicable institutional and governmental regulations concerning the ethical use of human volunteers were followed during this research.

Consecutive patients were recruited into each of the 3 groups:

- Group A-phacoemulsification group, receiving phacoemulsification, and intraocular lens (IOL) implantation;

- Group B - vitrectomy group, receiving pars plana vitrectomy, and other posterior segment procedures;

- Group C-combined surgery group, receiving phacoemulsification, IOL implantation, pars plana vitrectomy, and other posterior segment procedures.

Exclusion criteria were previously operated eyes, eyes with pre-existing corneal pathology, and eyes with poor vision precluding proper fixation for corneal topography.

Each patient underwent a complete preoperative ophthalmic examination, including refraction, best corrected visual acuity, anterior segment biomicroscopy, applanation tonometry, and fundal examination by indirect ophthalmoscopy. All eyes received computerised corneal topography (Eyesys Corneal Analysis System, EyeSys Technologies Inc.) preoperatively and at 3 months postoperatively. The machine was calibrated before the study and measurements were performed according to the manufacturer's instructions. Operators of the machine were masked according to the type of surgery that the patients received.

Simulated keratometric readings were used to calculate the pre- and postoperative topographic astigmatism amplitude. SIA was calculated by the difference between the pre- and postoperative astigmatism by the rectangular coordinate method using the Holladay-Cravy-Koch formula. ${ }^{11}$ The preoperative readings were measured within 4 weeks before the operation and postoperative readings were measured at 3 months after the operation. Surgically induced corneal topographic changes were analysed by evaluating 12 points situated at $1.5 \mathrm{~mm}$ from the centre of the cornea, corresponding a $3.0 \mathrm{~mm}$ optical zone. Surgically induced changes at every point were determined by the calculating the difference between pre- and postoperative corneal refractive power.

$\mathrm{K}$-induced was defined as the amplitude of the cylinder of the calculated SIA. The axis of the cylinder of the calculated SIA distribution was defined as follows: with-the-rule (WTR) for axis along $0^{\circ}$ to $30^{\circ}$ and $150^{\circ}$ to $179^{\circ}$, against-the-rule (ATR) for axis along $60^{\circ}$ to $120^{\circ}$, and oblique axis (OBL) for axis along $31^{\circ}$ to $59^{\circ}$ and $121^{\circ}$ to $149^{\circ}$.

\section{Surgical procedures}

All the cases were performed by a single surgeon (CYFY) from March 2001 to April 2002 using a standardised technique:

- Group A-phacoemulsification group. After limited peritomy and haemostasis with minimal cautery, a $3.0 \mathrm{~mm}$ wide self-sealing sclero-corneal tunnel was created using a diamond knife at 10 o'clock, $1.0 \mathrm{~mm}$ post-limbus. An additional puncture for the insertion of the spatula was made at the limbus at 2 o'clock. After phacoemulsification and irrigation/aspiration, a foldable $5.5 \mathrm{~mm}$ IOL (MA30BA, AcrySof Alcon) or a foldable $6.0 \mathrm{~mm}$ IOL (MA60BM, AcrySof Alcon) was implanted in the capsular bag. The $5.5 \mathrm{~mm}$ IOL was used for routine cases and the $6.0 \mathrm{~mm}$ IOL was used for cases with vitreo-retinal pathology likely to benefit from future peripheral fundal examination. The sclerocorneal tunnel was enlarged to $3.2 \mathrm{~mm}$ for cases requiring the $6.0 \mathrm{~mm}$ IOL. The sclero-corneal tunnel was left unsutured.

- Group B-vitrectomy group. After limited peritomy and haemostasis, three sclerotomies were made using a micro-vitreo-retinal blade at 2, 8, and 10 o'clock (right eye) or at 2, 4, and 10 o'clock (left eye), $3.5 \mathrm{~mm}$ post-limbus. The size of the sclerotomies was able to accommodate up to 19-gauge instruments. Vitrectomy and other intraocular manipulations, such as removal of epiretinal membranes, laser photocoagulation, fluid replacement, and intraocular gas/oil exchange to tamponade the retina were performed as required. At completion of intraocular procedures, the sclerotomies and the conjunctival wounds were closed with 7-0 polyglactin mattress suture (Vicryl, Ethicon, Norderstedt, Germany) under minimal tension.

- Group C-combined surgery group. After limited peritomy and haemostasis, phacoemulsification and IOL implantation using the $6.0 \mathrm{~mm}$ IOL was performed through a $3.2 \mathrm{~mm}$ wide self-sealing sclerocorneal tunnel at 10 o'clock, $1.0 \mathrm{~mm}$ post-limbus. The 
sclero-corneal tunnel was left unsutured. Pars plana vitrectomy and other intraocular manipulations were performed as in group B.

No attempt was made in any case to modify the preexisting astigmatism.

Postoperative treatment included a combination of gutt prednisolone acetate $1 \%$ and gutt olfloxacin $0.3 \%$ four times daily, tapered over 1 month. Antiglaucomatous medications were prescribed as necessary.

\section{Statistical analysis and sample size calculation}

The SPSS 12.0 program for Windows (SPSS Inc.) was used for all statistical analyses. Results were expressed as mean \pm SDs. Overall inter-groups differences were first compared using one-way analysis of variance (ANOVA). Post hoc pairwise comparisons using independent sample student t-test would be performed if significant overall inter-group differences were found. Bonferroni correction would be applied when indicated. A $P$ value less than 0.05 was considered statistically significant.

Assuming an inter-group K-induced difference of $0.50 \mathrm{D}(\mathrm{SD}=0.50 \mathrm{D})$ would be clinically meaningful, the estimated sample size in each group required to reach statistical significance of $5 \%$ with a power of $80 \%$ would be 16, for a two-sided hypothesis. Assuming a default rate of $20 \%, 20$ patients would be needed in each group.

\section{Results}

Twenty consecutive patients were recruited in each group. The cohort comprised of 31 men and 29 women with a mean age of 62.2 years \pm 8.2 (SD; range $23-88$ years). Patient demographics are summarised in Table 1. There were no statistically significant differences in age, sex, or operated eyes among the three groups. All patients were available for postoperative topography at 3 months.

All group A and group C patients underwent phacoemulsification due to visually impairing cataracts. The indications for vitrectomy for group B patients included macular pucker (7 eyes), nonclearing vitreous

Table 1 Patient demographics

\begin{tabular}{lccc}
\hline & $\begin{array}{c}\text { Group A } \\
\text { Phacoemulsification } \\
\text { alone }\end{array}$ & $\begin{array}{c}\text { Group B } \\
\text { Vitrectomy } \\
\text { alone }\end{array}$ & $\begin{array}{c}\text { Group C } \\
\text { Combined } \\
\text { phacoemulsification } \\
\text { and vitrectomy }\end{array}$ \\
\hline$N$ & 20 & 20 & 20 \\
$\begin{array}{l}\text { Mean age } \pm \text { SD } \\
\text { (years) }\end{array}$ & $69.1 \pm 10.0$ & $48.7 \pm 14.2$ & $69.5 \pm 8.7$ \\
$\begin{array}{l}\text { Sex (M:F) } \\
\text { Eyes (R:L) }\end{array}$ & $7: 13$ & $10: 10$ & $14: 6$ \\
\hline
\end{tabular}

haemorrhage (4 eyes), tractional retinal detachment (4 eyes), rhegmatogenous retinal detachment (4 eyes), and removal of intraocular ocular foreign body ( 1 eye); and for group C patients, macular pucker (9 eyes), nonclearing vitreous haemorrhage (8 eyes), and macular hole (3 eyes).

The pre- and postoperative topographic astigmatic amplitudes are listed in Table 2. The mean K-induced were $0.19 \pm 0.14 \mathrm{D}, 0.17 \pm 0.11 \mathrm{D}$ and $0.23 \pm 0.19 \mathrm{D}$ for groups $\mathrm{A}, \mathrm{B}$, and $\mathrm{C}$, respectively. The range of $\mathrm{K}$-induced for the entire cohort was $0.00-0.77 \mathrm{D}$. Visual acuity improved in 100,70, and $70 \%$ of eyes in groups A, B, and $C$, respectively.

No overall statistically significant differences in the pre- and postoperative topographic astigmatic amplitudes were found. Although combined surgery was associated with the highest mean K-induced compared to when either procedure was performed alone, the difference was statistically insignificant (Table 2, $P>0.05)$. As there were no overall inter-groups differences, post hoc pairwise comparisons were not further tested.

Figure 1 shows the pre- and postoperative axis distributions. Shifts to oblique meridians were noted in approximately $10 \%$ of cases in all three groups. These shifts were consistent with that induced by the sclerocorneal tunnels and/or the sclerotomies. Since the mean K-induced in each group was small, these shifts should be interpreted with caution.

\section{Discussion}

In combined phacoemulsification and vitrectomy, astigmatism may be induced by either or both procedures. Our results show that even when combined phacoemulsification and vitrectomy is associated with the greatest SIA, the absolute amount of induced astigmatism is still fairly small and is not statistically different to that induced by either procedure alone.

In the present study, we have chosen a sclero-corneal tunnel incision instead of the more commonly utilised clear corneal incision for phacoemulsification. We believe sclero-corneal phacoemulsification is more appropriate if concurrent posterior segment procedures are to be performed, since it is usually associated with less intraoperative corneal trauma and therefore better intraoperative visibility from less corneal oedema. This is particularly important for prolonged vitreo-retinal procedures. Sclero-tunnel incisions also provide higher standard for comparison as they generally induce less corneal astigmatism. ${ }^{4,12}$ Our mean K-induced of $0.19 \pm 0.14 \mathrm{D}$ at 3 months postoperatively compares favourably with that of $0.10-0.46 \mathrm{D}$ reported in the literature. ${ }^{4-6}$ 
Table 2 Pre- and postoperative topographic astigmatism amplitude and K-induced for groups A, B, and C

\begin{tabular}{|c|c|c|c|c|c|c|c|c|c|}
\hline \multirow[t]{3}{*}{ Patient no. } & \multicolumn{9}{|c|}{ Topographic astigmatism amplitude (D) } \\
\hline & \multicolumn{3}{|c|}{ Preoperative } & \multicolumn{3}{|c|}{ Postoperative } & \multicolumn{3}{|c|}{ K-induced ${ }^{\mathrm{a}}$} \\
\hline & Group A & Group B & Group C & Group A & Group B & Group C & Group A & Group B & Group C \\
\hline 1 & 1.01 & 0.51 & 0.45 & 0.87 & 0.56 & 0.45 & 0.14 & 0.12 & 0.00 \\
\hline 2 & 0.50 & 0.49 & 0.37 & 0.16 & 0.67 & 0.45 & 0.34 & 0.22 & 0.08 \\
\hline 3 & 0.90 & 0.17 & 0.38 & 1.06 & 0.28 & 0.21 & 0.29 & 0.39 & 0.18 \\
\hline 4 & 0.17 & 1.29 & 0.33 & 0.16 & 1.97 & 0.39 & 0.09 & 0.15 & 0.10 \\
\hline 5 & 0.18 & 0.40 & 0.39 & 0.42 & 0.16 & 0.34 & 0.24 & 0.29 & 0.08 \\
\hline 6 & 0.25 & 1.02 & 0.74 & 0.24 & 1.33 & 0.80 & 0.06 & 0.37 & 0.35 \\
\hline 7 & 0.93 & 0.68 & 0.46 & 0.80 & 0.66 & 0.64 & 0.16 & 0.07 & 0.19 \\
\hline 8 & 0.27 & 2.11 & 1.24 & 0.38 & 2.11 & 0.71 & 0.13 & 0.22 & 0.65 \\
\hline 9 & 0.75 & 0.26 & 0.32 & 0.75 & 0.29 & 0.62 & 0.00 & 0.05 & 0.77 \\
\hline 10 & 0.11 & 1.53 & 0.75 & 0.18 & -1.57 & 0.83 & 0.07 & 0.32 & 0.14 \\
\hline 11 & 0.72 & 0.56 & 0.48 & 0.82 & 0.59 & 0.76 & 0.10 & 0.12 & 0.02 \\
\hline 12 & 0.37 & 0.27 & 1.25 & 0.30 & 0.40 & 1.32 & 0.24 & 0.17 & 0.11 \\
\hline 13 & 0.42 & 0.75 & 0.66 & 0.41 & 0.76 & 0.41 & 0.07 & 0.08 & 0.26 \\
\hline 14 & 1.12 & 0.66 & 0.27 & 0.82 & 0.66 & 0.43 & 0.33 & 0.07 & 0.20 \\
\hline 15 & 0.34 & 0.27 & 0.44 & 0.86 & 0.37 & 0.48 & 0.52 & 0.17 & 0.13 \\
\hline 16 & 0.38 & 0.79 & 1.31 & 0.37 & 0.88 & 1.50 & 0.04 & 0.20 & 0.39 \\
\hline 17 & 0.39 & 0.88 & 0.84 & 0.00 & 0.86 & 0.60 & 0.39 & 0.15 & 0.32 \\
\hline 18 & 0.62 & 1.29 & 0.80 & 0.32 & 1.13 & 0.68 & 0.31 & 0.16 & 0.16 \\
\hline 19 & 0.44 & 0.48 & 0.77 & 0.67 & 0.48 & 0.68 & 0.24 & 0.00 & 0.22 \\
\hline 20 & 0.34 & 0.12 & 0.96 & 0.33 & 0.18 & 0.84 & 0.04 & 0.08 & 0.25 \\
\hline $\begin{array}{l}\text { Mean } \pm \text { SD } \\
P \text { value }\end{array}$ & $0.51 \pm 0.30$ & $\begin{array}{c}0.73 \pm 0.51 \\
0.21\end{array}$ & $0.66 \pm 0.33$ & $0.50 \pm 0.30$ & $\begin{array}{c}0.64 \pm 0.74 \\
0.54\end{array}$ & $0.66 \pm 0.31$ & $0.19 \pm 0.14$ & $\begin{array}{c}0.17 \pm 0.11 \\
0.45\end{array}$ & $0.23 \pm 0.19$ \\
\hline
\end{tabular}

${ }^{a}$ Amplitude of cylinder of calculated surgically induced astigmatism (Holladay-Cravy-Koch formula). ${ }^{11}$

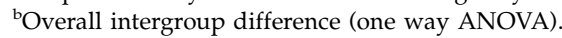

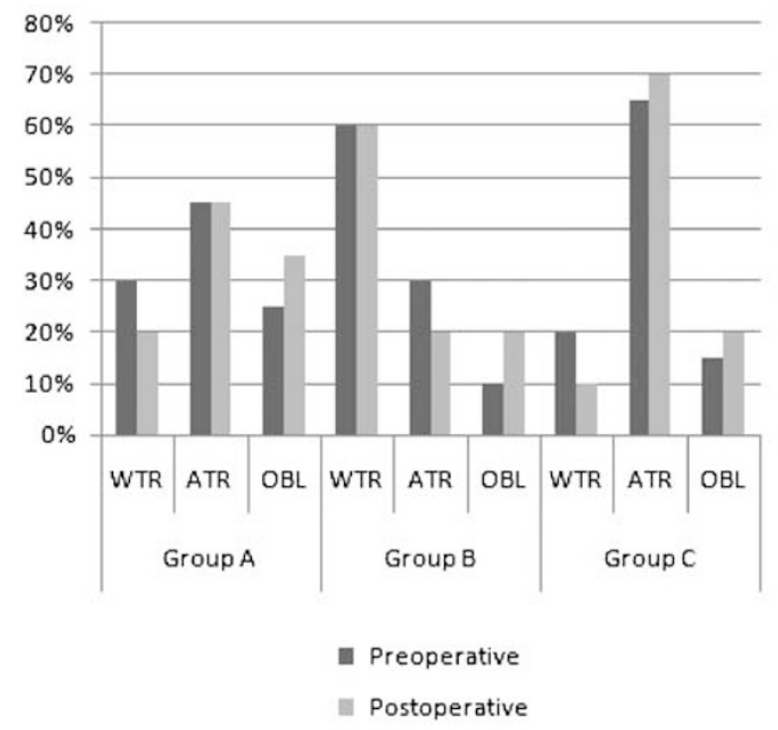

Figure 1 Pre- and postoperative axis distribution for groups A, $\mathrm{B}$, and C. WTR, with-the-rule, axis $0^{\circ}$ to $30^{\circ}$ and $150^{\circ}$ to $179^{\circ}$; ATR, against-the-rule, axis $60^{\circ}$ to $120^{\circ}$; and OBL, oblique axis, axis $31^{\circ}$ to $59^{\circ}$ and $121^{\circ}$ to $149^{\circ}$.
Most studies so far reported only transient SIA when vitrectomy is performed alone..$^{7-10}$ This is in contrast to other vitreo-retinal procedures, such as scleral buckling, which are associated with significant increases in both anterior and posterior corneal elevation ${ }^{13}$ as well as significantly increased SIA for long periods of time (>6 months). ${ }^{14-17}$

Several reasons have been proposed to explain the apparently insignificant SIA in vitrectomised eyes, including the relative posterior position of sclerotomies in respect to the cornea, the negligible use of cautery for haemostasis and the tensile strengths as well as the number of sutures used in closure of sclerotomies. ${ }^{8}$ Great care has been taken to standardise the technique and minimise these potential sources of astigmatism in the present study. To further minimise vitrectomy-induced astigmatism, we advocate against excessive cauterisation and excessive tightening of the sclerotomy sutures. We also suggest the use of polyglactin sutures in sclerotomy closure, as these sutures generally lose their tensile strengths after 4 weeks from progressive chemical hydrolysis. ${ }^{8}$ Any induced astigmatism due to overtightening of sclerotomy sutures will only therefore be transient. 
It would be interesting to assess the amount of SIA with the new sutureless vitrectomy systems, such as the 25 - and the 23-gauge systems. Kadonosono ${ }^{18}$ compared the SIA of 20- vs 25-gauge system in 67 patients with epiretinal membrane. It was found that the 25 -gauge system induced significantly less astigmatism at 1 month postoperatively, as compared to the 20-gauge system. This difference was statistically insignificant at 6 months. The actual amount of SIA was however not provided in the study. The 23-gauge system involves the creation of tangential transconjunctival scleral tunnels ${ }^{19}$ instead of perpendicular sclerotomies as in the 20- and the 25-gauge systems. Although head-to-head comparisons between these different incisional techniques are lacking, it has been suggested that tunnel incisions may be superior as these only lead to slight postoperative reaction and therefore minimal SIA. ${ }^{19}$

Our study had certain limitations. Firstly, inclusion bias could have confounded our findings. We attempted to minimise these biases by recruiting consecutive patients. Secondly, our results were only based on a single corneal topographic measurement at 3 months. We did not perform topographic measurements before 3 months because these measurements may be inaccurate due to corneal oedema, tear film instability, and chemosis, all of which are common in the early postoperative period in vitrectomised eyes. Visual acuity in the early postoperative period may also be affected by internal tamponade, precluding proper fixation during corneal topographic examination. Previous studies on vitrectomy patients ${ }^{7-9}$ have shown that although there are significant astigmatic changes during the early postoperative period, these changes usually regress to smaller amplitudes within weeks postoperatively. Nonetheless, continued follow-ups of patients are necessary to monitor the long-term refractive stability of these procedures.

In conclusion, our study showed that combined phacoemulsification and vitrectomy induced no significant corneal astigmatism compared to when either procedure is performed alone. With this knowledge in mind, other refractive procedures, such as astigmatic keratotomy, could be considered for patients with concurrent high corneal astigmatism, cataract, and vitreo-retinal pathology requiring surgery. Future studies assessing the efficacy of these refractive procedures in the context of combined phacoemulsification and vitrectomy seem warranted.

\section{References}

1 Chung TY, Chung H, Lee JH. Combined surgery and sequential surgery comprising phacoemulsification, pars plana vitrectomy and intraocular lens implantation. J Cataract Refract Surg 2002; 28: 2001-2005.

2 Koenig SB, Mieler WF, Han DP, Abrams GW. Combined phacoemulsification, pars plana vitrectomy and posterior chamber intraocular lens insertion. Arch Ophthalmol 1992; 110: 1101-1104.

3 Demetriades AM, Gottsch JD, Thomsen R, Azab A, Stark WJ, Campochiaro PA et al. Combined phacoemulsification, intraocular lens implantation and vitrectomy for eyes with coexisting cataract and vitreoretinal pathology. Am J Ophthalmol 2003; 135: 291-296.

4 Beltrame G, Salvetat ML, Chizzolini M, Driussi G. Corneal topographic changes induced by different oblique cataract incisions. J Cataract Refract Surg 2001; 27(5): 720-727.

5 Olsen T, Dam-Johansen M, Bek T, Hjortdal JO. Corneal versus scleral tunnel incision in cataract surgery: a randomized study. J Cataract Refract Surg 1997; 23(3): 337-341.

6 Gross RH, Miller KM. Corneal astigmatism after phacoemulsification and lens implantation through unsutured scleral and corneal tunnel incisions. Am J Ophthalmol 1996; 121(1): 57-64.

7 Weinberger D, Lichter H, Loya N, Axer-Siegel R, Muzmacher L, Gabbay U et al. Corneal topographic changes after retinal and vitreous surgery. Ophthalmology 1999; 106(8): 1521-1524.

8 Wirbelauer $\mathrm{C}$, Hoerauf $\mathrm{H}$, Roider J, Laqua H. Corneal shape changes after pars plana vitrectomy. Graefes Arch Clin Exp Ophthalmol 1998; 236(11): 822-828.

9 Domniz YY, Cahana M, Avni I. Corneal surface changes after pars plana vitrectomy and scleral buckling surgery. J Cataract Refract Surg 2001; 27(6): 868-872.

10 Jampel HD, Thompson JT, Nunez M, Michels RG. Corneal astigmatic changes after pars plana vitrectomy. Retina 1987; 7: 223-226.

11 Holladay JT, Cravy TV, Koch DD. Calculating the surgically induced refractive change following ocular surgery. J Cataract Refract Surg 1992; 18(5): 429-443.

12 Chipont-Benabent E, Artola Roig A, Perez-Santonja JJ, Guisbert Medel M, Alió Sanz JL. Astigmatism induced by intrastromal corneal suture after small incision phacoemulsification. J Cataract Refract Surg 1998; 24(4): 519-523.

13 Sinha R, Sharma N, Verma L, Pandey RM, Vajpayee RB. Corneal topographic changes following retinal surgery. BMC Ophthalmol 2004; 4(1): 10.

14 Hayashi H, Hayashi K, Nakao F, Hayashi F. Corneal shape changes after scleral buckling surgery. Ophthalmology 1997; 104(5): 831-837.

15 Goel R, Crewdson J, Chignell AH. Astigmatism following retinal detachment surgery. Br J Ophthalmol 1983; 67(5): 327-329.

16 Tomidokoro A, Oshika T, Kojima T. Corneal astigmatism after scleral buckling surgery assessed by Fourier analysis of videokeratography data. Cornea 1998; 17(5): 517-521.

17 Oshika T, Tomidokoro A, Maruo K, Tokunaga T, Miyata N. Quantitative evaluation of irregular astigmatism by fourier series harmonic analysis of videokeratography data. Invest Ophthalmol Vis Sci 1998; 39(5): 705-709.

18 Kadonosono K, Yamakawa T, Uchio E, Yanagi Y, Tamaki Y, Araie M. Comparison of visual function after epiretinal membrane removal by 20-gauge and 25-gauge vitrectomy. Am J Ophthalmol 2006; 142(3): 513-515.

19 Eckardt C. Transconjunctival sutureless 23-gauge vitrectomy. Retina 2005; 25(2): 208-211. 